\title{
HOUSEHOLD SOLID WASTE RECYCLING INDUCED PRODUCTION VALUES AND EMPLOYMENT OPPORTUNITIES IN TAIWAN
}

\author{
Esher $\mathrm{Hsu}^{1}$ and Chen-Ming Kuo ${ }^{2}$ \\ ${ }^{1}$ Department. of Statistics, National Taipei Univ., Taipei 104, Taiwan \\ ${ }^{2}$ Department. of Mechanical Eng., I-Shou Univ., Kaohsiung 84008, Taiwan
}

\begin{abstract}
Household solid waste recycling has been a major policy of the Taiwan Environmental Protection Administration. Production values and employment opportunities from recycling are not only a major focus of Taiwan's Congress, but also the major goal of recycling policies for the EPA. In this study, production values and employment opportunities induced by household solid waste recycling were estimated from a sampling survey. The estimated production values in 1998 were NT\$26.9 (USD\$0.27) billion from collection/sorting business and NT\$44.6 (USD\$1.27) billion from the recycling industry. Total estimated added value was approximately NT $\$ 35$ (USD\$1) billion, of which NT\$15.5 (USD\$0.44) billion was from the collection/sorting business and $\$ 19.5$ (USD\$0.56) billion was from recycling. The collection/sorting business represents about $0.28 \%$ of gross domestic product (GDP) in the service sector, and the recycling industry represents about $0.8 \%$ of GDP in manufacturing sector in 1998. The combined employment was 189,551 , of which 182,538 was collection/sorting business (3.69\% of service jobs) and 7,013 positions ( $0.27 \%$ manufacturing jobs) in 1998.
\end{abstract}




\section{Introduction}

According to the official statistical analysis [1], the total household waste generated in Taiwan in 1999 was 8.88 million tons with an average $1.082 \mathrm{~kg}$ daily waste produced per person. In a small island with limited land, resources, and a high population density, such a high volume of waste generation has caused serious environmental problems. In recent years, spurred by the lack of landfill sites and the increasing cost of waste disposal, the reduction of the volume of waste disposal has become an important goal of public policy while recycling of solid waste has become an increasingly urgent issue in Taiwan. Therefore, household solid waste recycling has become the major policy of Taiwan Environmental Protection Administration (EPA).

The "4-in-1" recycling system was implemented by Taiwan EPA on March 3, 1997, to integrate 4 major players, namely, the communities, the local government solid waste cleaning crews, the recycling and waste disposal industry, and the recycling foundation. The "4 in 1" goal is to improve the efficiency of recycling. Under this recycling system, the recycling of waste packaging containers and solid waste products is required. The waste packaging containers are defined as iron cans, aluminum cans, glass bottles, plastic containers, paper containers, aluminum foiled paper packs. The solid waste products are defined as batteries, tires, lubricant oil, motor vehicles, home appliances (TV sets, refrigerators, air conditions, and washing machines), and computers. In order to compensate this household recycling system, the EPA has charged associated manufacturers and importers recycling fees of around NT\$4.6 (USD0.13) billion ${ }^{1}$ in 1999 [1]. Recently, the payers of these recycling fee and congressmen/congresswomen have questioned the performance and effectiveness of this recycling system and the expense of the recycling fees. How to evaluate the recycling performance and effectiveness has become the key issue for EPA.

In this study, production values and employment opportunities induced by the household waste recycling were analyzed to evaluate the recycling performance and effectiveness. The production values and employment opportunities were estimated based on a sampling survey where the ratio estimation was used to increase the precision of estimation. Survey results show that the estimated production values in 1998 were NT\$26.9 (USD\$0.27) billion from collection/sorting business and NT\$44.6 (USD\$1.27) billion from the recycling industry. Total estimated added value was approximately NT\$35 (USD\$1) billion, of which NT\$15.5 (USD\$0.44) billion was from the collection/sorting business and \$19.5 (USD\$0.56) billion was from recycling. The combined employment was 189,551, of which 182,538 was collection/sorting business (3.69\% of service jobs) and 7,013 positions $(0.27 \%$ manufacturing jobs) in 1998.

Based on the background data of employees in the recycling market, it was found that a high percentage of employees have a low level of education and are of older age. That implies that the recycling market in Taiwan provides potential job opportunities for older, less-educated laborers.

\footnotetext{
${ }^{1} 1 \mathrm{USD}^{\sim} 35$ NT\$ as of February 2002.
} 


\section{Methodology}

The aim of present study is to estimate production values and employment opportunities induced by household waste recycling in Taiwan. During the survey period, year 1999, the list of mandatory recycling items includes waste packaging containers and solid waste products as already mentioned earlier and the target survey population includes all related collectors and recycling plants of household solid waste in Taiwan, which consists of 1,926 collectors and 146 recycling plants.

Systematic sampling combined with stratification was used to select a probability sample of collectors for each recycling item, whereas, the ratio estimator was used to estimate the corresponding production values and employment opportunities. The fundamental principle of sampling survey theory [2] states that if sampling units can be classified into strata that are internally selected from each stratum, then the variance of overall estimators may be reduced. Due to the influence of socioeconomic characteristics and the environmental policies of local government on the waste recycling system, collectors were stratified based on counties. It is commonly believed that the production values and employment opportunities vary considerably with different counties, thus there are 23 strata in all. From each county, a systematic sample with 455 collectors was selected, and consequently, these selected collectors were surveyed to obtain related information of production values and employment opportunities of collecting recyclable household waste $[3]$.

In Taiwan, the number and scale of recycling plants varies considerably among the items listed for required recycling. The variations were considered in the calculation. A small number of large recycling plants handle a larger volume of many of the required recyling items. On the other hand, certain recycling items are handled in a larger number of smaller recycling plants. Thus, the sampling with probability proportional to size was used to select the sample. There were totally 81 selected recycling plants, which were surveyed to obtain related information of their production values and employment opportunities regarding their waste recycling. In the surveying of both collectors and recycling plants, face-to-face interviews were conducted to collect data in order to ensure the precision of the estimates and reduce the non-response rate.

In the statistical analyses, the ratio estimation was used to estimate the recycled quantities first, and then the production values and employment opportunities induced by household waste recycling were estimated via the estimated recycled quantities. The ratio estimation was used in this study because of the following reasons: (1) the true population size of recycling plants (collectors) is unknown, (2) the audited amount of household waste recycling is known, and (3) the audited amount and recycling amount are highly correlated. Under this situation, by using the auxiliary variable, auditing amount, the precision of the estimates could be increased. Although the ratio estimation is a biased estimation for large sample size, the bias could be ignored. Hedayat and Sinha [4] mentioned that increasing sample size is one of the methods to reduce the bias. In this study, the large sample size, given the audited amount in 1998 and the positive linear correlation between the audited amount and recycled amount provided the ideal conditions to use ratio estimation. It is believed that using the audited amount as an auxiliary variable to estimate the recycled 
amount will increase the precision of the estimation under this situation. The estimation methods are described as followings:

\section{Estimation of recycled amount}

The ratio of audited amount to recycled amount is estimated first by using the sample data as given by

$$
\hat{R}_{h}=\frac{\sum_{i=1}^{n_{h}} x_{h i}}{\sum_{i=1}^{n_{h}} y_{h i}}
$$

where $x_{h i}$ and $y_{h i}$ are respectively the audited amount and recycled amount of the $i^{\text {th }}$ collector (recycling plant) for the $h^{\text {th }}$ item, and $\hat{R}_{h}$ is the estimated ratio of recycling item $h$. Then we estimate the total recycled amount based on the estimated $R$. The estimate of total recycled amount $Y_{h}$ is given by

$$
\hat{Y}_{h}=X_{h} / \hat{R}_{h}
$$

where $X_{h}$ is the audited amount of population in 1998 for recycled item $h$, and $\hat{Y}_{h}$ is the estimated total recycled amount for recycled item $h$.

$\underline{\text { Estimations of production values, value-added, and employment opportunities }}$

The estimated total recycled amount in equation (2) is used to estimate production values and employment opportunities as shown in the following equations

$$
\begin{aligned}
& \hat{V}_{h}=\hat{Y}_{h} \cdot \hat{P}_{h} \\
& \hat{L}_{h}=\hat{Y}_{h} \cdot \hat{U}_{h}
\end{aligned}
$$

where $\hat{P}_{h}$ is the estimated unit price of recycled material for recycled item $h$, and $\hat{V}_{h}$ is the estimated production value; $\hat{U}_{h}$ is the estimated labor input per unit recycled amount for item $h$, and $\hat{L}_{h}$ is the estimated employment induced.

In principle, value-added represents gross domestic production (GDP) based on market value, which is calculated by taking off intermediate costs from production value. In this study, value-added for each item is generated by multiplying production value with corresponding value-added rate; while the value-added rate is calculated based on "National Income of Taiwan" issued by the Directorate-General of Budgets, Accounting, and Statistics in 1998 [5]. 


\section{Estimated production value and value-added of recycling market}

Based on a sampling survey and the ratio estimation described above, this study shows that the Taiwan recycling market in 1998, which includes household waste container recycling and solid waste recycling, generated about NT\$26.9 (USD\$0.27) billion production values for waste collectors and NT\$44.6 (USD\$1.27) billion for recyclers, as shown in Table I. The data show that waste iron can collectors and waste aluminum can recyclers are the greatest contributors of production value in the collecting business and recycling industry, respectively. The waste iron can collectors contributed about 33\% production value for collecting side, and the waste aluminum can recyclers contributed about $42 \%$ production value for recycling side.

Also shown in Table I, the estimated value-added shows that the Taiwan recycling market in 1998 generated about NT\$35 (USD\$1) billion. Of this total, collectors contributed about NT\$15.5 (USD\$0.44) billion and recyclers NT\$19.5 (USD\$0.56) billion, respectively (see Table I for details). The waste collectors contributed about $0.28 \%$ of GDP to the service sector, and the recyclers contributed about $0.8 \%$ of GDP in the manufacturing industrial sector in 1998.

\section{Estimated employment opportunities of recycling market}

Table II reveals that the recycling market in Taiwan provides 189,551 employment opportunities. Compared with the total employed population of Taiwan in 1998 of 9.289 million [6], the recycling market is around $2 \%$ of total employed population in Taiwan. The collection business part of the total was 182,538 and this amounts to about $3.69 \%$ of total employed population in the service sector. The recycling industry part of the total was 7,013 positions which amounts to around $0.27 \%$ of the total employed population of the manufacturing sector in 1998. The background of employees in recycling market is shown in Table III and IV for collection business and recycling industry, respectively. Table III indicates that the employees of the collection businesses have low-level education and high age for waste container collectors. Results also show that high percentages of waste container collectors have only an elementary school education or less, and their ages average more than 50. In contrast, the solid waste collector employees are middle aged and have middle-level education. High percentages of solid waste collectors have a high school education, and their ages lie between 30 and 50. Table IV shows that the employees of the waste recycling industry have a high percentage who obtained a middle-level education and are of middle age. The age of employees in the recycling sector tended to be much younger than that of employees in the collection sector, while the education level of the recycling sector was also higher than that of the collection sector. According to the results, the average education level in the recycling market is below high school level. This data implies that the recycling market in Taiwan presently provides the benefits of job opportunities for low-level educated and high age laborers and in the near future, the recycling market may provide even larger potential employment opportunities for unemployed, less educated, older laborers. 
Table I: Estimated production values and value-added of recycling market (1998)

Unit: million NT\$

\begin{tabular}{|l|r|r|r|r|r|}
\hline \multicolumn{1}{|c|}{ Recycling Item } & \multicolumn{2}{|c|}{ Production Values } & \multicolumn{3}{c|}{ Value-added } \\
\hline Waste Containers & Collectors & Recyclers & Collectors & Recyclers & Subtotal \\
\hline Iron cans & $\mathbf{3 , 1 1 4}$ & $\mathbf{3 , 8 5 4}$ & $\mathbf{1 , 7 9 3}$ & $\mathbf{1 , 3 8 3}$ & $\mathbf{3 , 1 7 6}$ \\
\hline Aluminum cans & 1,023 & 384 & 589 & 143 & 732 \\
\hline Paper containers & 700 & 1,630 & 403 & 606 & 1,009 \\
\hline Glass bottles & 333 & 3 & 192 & 1 & 193 \\
\hline Plastic containers & 139 & 1,053 & 80 & 356 & 436 \\
\hline Pesticide containers & 884 & 769 & 509 & 272 & 781 \\
\hline Other Solid Wastes & $\mathbf{2 3 , 7 3 9}$ & $\mathbf{4 0 , 7 8 0}$ & $\mathbf{1 3 , 6 6 1}$ & $\mathbf{1 8 , 1 5 5}$ & $\mathbf{3 1 , 8 1 6}$ \\
\hline Automobiles & 239 & 21 & 138 & 7 & 145 \\
\hline Tires & 1,169 & 289 & 672 & 104 & 776 \\
\hline Lubricant oil & 32 & 39,731 & 18 & 17,792 & 17,810 \\
\hline Lead Batteries & 22,299 & 739 & 12,833 & 252 & 13,085 \\
\hline Total & $\mathbf{2 6 , 8 5 3}$ & $\mathbf{4 4 , 6 3 4}$ & $\mathbf{1 5 , 4 5 4}$ & $\mathbf{1 9 , 5 3 8}$ & $\mathbf{3 4 , 9 9 2}$ \\
\hline
\end{tabular}

Table II: Estimated employment opportunities of recycling market (1998)

\begin{tabular}{|l|r|r|r|}
\hline \multicolumn{1}{|c|}{ Recycling Item } & \multicolumn{3}{c|}{ Unit: persons } \\
\hline & Collectors & Recyclers & Total \\
\hline Waste Containers & $\mathbf{1 5 , 8 1 6}$ & $\mathbf{2 , 5 4 0}$ & $\mathbf{1 8 , 3 5 6}$ \\
\hline Iron cans & 5,670 & 56 & 5,726 \\
\hline Aluminum cans & 2,978 & 214 & 2,192 \\
\hline Paper containers & 1,908 & 59 & 1,967 \\
\hline Glass bottles & 851 & 1,610 & 2,461 \\
\hline Plastic containers & 4,227 & 595 & 4,822 \\
\hline Pesticide containers & 182 & 6 & 188 \\
\hline Other Solid Wastes & $\mathbf{1 6 6 , 7 2 2}$ & $\mathbf{4 , 4 7 3}$ & $\mathbf{1 7 1 , 1 9 5}$ \\
\hline Automobiles & 1,348 & 15 & 1,363 \\
\hline Tires & 6,679 & 486 & 7,165 \\
\hline Lubricant oil & 961 & 3,915 & 4,876 \\
\hline Lead Batteries & $\mathbf{1 5 7 , 7 3 4}$ & 57 & 157,791 \\
\hline Total & $\mathbf{1 8 2 , 5 3 8}$ & $\mathbf{7 , 0 1 3}$ & $\mathbf{1 8 9 , 5 5 1}$ \\
\hline
\end{tabular}


Table III: Background of employees in Taiwan recycling market - collection business

\begin{tabular}{|l|r|r|r|r|r|r|}
\hline \multicolumn{1}{|c|}{ Recycling Item } & \multicolumn{3}{|c|}{ Employees of Waste Collection } \\
\hline & \multicolumn{3}{|c|}{ Education } & \multicolumn{3}{c|}{ Age } \\
\hline & $\begin{array}{c}\text { Elementary school } \\
\text { and below }\end{array}$ & High school & $\begin{array}{c}\text { College and } \\
\text { above }\end{array}$ & Below 30 & $30 \sim 50$ & Above 50 \\
\hline Waste Containers & $\mathbf{5 5 . 9}$ & $\mathbf{4 0 . 8}$ & $\mathbf{3 . 2}$ & $\mathbf{1 3 . 3}$ & $\mathbf{5 3 . 8}$ & $\mathbf{3 2 . 9}$ \\
\hline Iron cans & 57.5 & 37.9 & 4.6 & 12.4 & 45.9 & 41.7 \\
\hline Aluminum cans & 50.1 & 47.9 & 2.0 & 8.6 & 46.9 & 44.5 \\
\hline Paper containers & 56.5 & 37.8 & 5.7 & 14.5 & 54.5 & 30.9 \\
\hline Glass bottles & 54.9 & 44.1 & 0.9 & 10.8 & 37.4 & 51.8 \\
\hline Plastic containers & 59.2 & 39.2 & 1.6 & 6.5 & 47.5 & 46.0 \\
\hline Pesticide containers & 24.6 & 74.1 & 1.3 & 19.1 & 56.2 & 24.7 \\
\hline Other Solid Wastes & $\mathbf{4 2 . 2}$ & $\mathbf{4 1 . 7}$ & $\mathbf{1 6 . 1}$ & $\mathbf{2 6 . 4}$ & $\mathbf{5 4 . 8}$ & $\mathbf{1 8 . 8}$ \\
\hline Automobiles & 38.4 & 51.1 & 10.5 & 24.1 & 54.9 & 21.0 \\
\hline Tires & 13.4 & 63.4 & 23.2 & 38.1 & 55.7 & 6.2 \\
\hline Lubricant oil & 5.3 & 73.9 & 20.8 & 38.9 & 54.6 & 6.5 \\
\hline Lead Batteries & 43.7 & 40.5 & 15.8 & 25.8 & 54.8 & 19.4 \\
\hline
\end{tabular}

Table IV: Background of employees in Taiwan recycling market - recycling industry

\begin{tabular}{|l|r|r|r|r|r|r|}
\hline \multicolumn{1}{|c|}{ Recycling Item } & \multicolumn{3}{|c|}{ Employees of Waste Recycling Plants } \\
\hline & \multicolumn{3}{|c|}{ Education } & \multicolumn{3}{c|}{ Age } \\
\hline & $\begin{array}{c}\text { Elementary school } \\
\text { and below }\end{array}$ & High school & $\begin{array}{c}\text { College and } \\
\text { above }\end{array}$ & Below 30 & $30 \sim 50$ & Above 50 \\
\hline Waste Containers & $\mathbf{2 4 . 8 8}$ & $\mathbf{5 7 . 2 4}$ & $\mathbf{1 7 . 8 8}$ & $\mathbf{3 7 . 2 1}$ & $\mathbf{5 3 . 0 7}$ & $\mathbf{9 . 7 2}$ \\
\hline Iron cans & 51.21 & 44.32 & 3.97 & 6.72 & 89.14 & 4.14 \\
\hline Aluminum cans & 4.39 & 85.37 & 10.24 & 30.81 & 60.39 & 8.80 \\
\hline Paper containers & 29.92 & 54.51 & 15.57 & 26.17 & 59.40 & 14.50 \\
\hline Glass bottles & 29.83 & 48.07 & 22.10 & 38.12 & 53.59 & 8.29 \\
\hline Plastic containers & 16.09 & 73.26 & 10.65 & 40.84 & 45.19 & 13.97 \\
\hline Pesticide containers & 16.67 & 66.66 & 16.67 & 67.86 & 32.14 & 0 \\
\hline Other Solid Wastes & $\mathbf{4 . 8 1}$ & $\mathbf{6 0 . 8 7}$ & $\mathbf{3 4 . 3 2}$ & $\mathbf{3 . 0 6}$ & $\mathbf{7 1 . 6 5}$ & $\mathbf{2 5 . 2 9}$ \\
\hline Automobiles & 0.00 & 84.60 & 15.40 & 46.15 & 38.46 & 15.38 \\
\hline Tires & 11.90 & 76.92 & 11.19 & 22.24 & 65.50 & 12.26 \\
\hline Lubricant oil & 4.01 & 58.78 & 37.22 & 0.57 & 72.13 & 27.30 \\
\hline Lead Batteries & 0.00 & 63.80 & 36.20 & 0.00 & 100.00 & 0.00 \\
\hline
\end{tabular}

\section{Conclusions}

Taiwan EPA's “4-in-1" recycling system has been implemented since 1997. Due to the large amount of funding for recycling, the performance and effectiveness of reccyling has become an important issue for the fund payers, budget auditors (congressmen/congresswomen), and EPA. The aim of this study was to evaluate the recycling performance and effectiveness based on the production values and employment opportunities 
provided by the recycling market.

Results show that Taiwan recycling market in 1998 generated NT\$26.9 (USD\$0.27) billion from collection/sorting business and NT\$44.6 (USD\$1.27) billion from the recycling industry. Total estimated added value was approximately NT\$35 (USD\$1) billion, of which NT\$15.5 (USD\$0.44) billion was from the collection/sorting business and NT\$19.5 (USD\$0.56) billion was from recycling. The collection/sorting business represents about $0.28 \%$ of gross domestic product (GDP) in the service sector, and the recycling industry represents about $0.8 \%$ of GDP in manufacturing sector in 1998. Moreover, results also show that the recycling market provided 189,551, which is around $2 \%$ of total employed population in Taiwan. Of this total, 182,538 was collection/sorting business (3.69\% of service jobs) and 7,013 positions (0.27\% manufacturing jobs) in 1998 .

The background of employees in the recycling market shows that a high percentage of employees have a low-level of education and are older in age. That implies that the recycling market in Taiwan provides potential jobs for a part of the population that would be able to benefit from these opportunities.

Similar to other developed countries, the industrial structure has changed in Taiwan. Currently, high technology industries increasingly dominate the Taiwan economy, while the traditional industries are experiencing recession. The rising of unemployment rate is accelerated by the unemployed laborers from traditional industries. It is increasingly difficult to obtain a job in the high technology industries especially for those older unemployed laborers with a low-level of education. According to this study, the average education level in recycling industries is below the high school level. In the near future, the recycling industries may provide an even larger potential of employment opportunities for those low-level educated laborers. Although the collection and recycling industry has many problems to solve, the recycling system implemented by the government has significant potential to imrpove economic efficiency by way of the production values generated by collection and recycling of refuse and waste and the added benefits of potential employment opportunities. The government program to require the collection and recycling of household waste has stimulated the development of the waste recycling industry and that will also bring environmental benefits to the country of a cleaner landscape, better use of land areas, and employment for older laborers.

\section{Acknowledgements}

The first author (Esher Hsu) would like to acknowledge that Taiwan EPA with project number EPA-044-880-129 support this research. 


\section{References}

1. "Environmental Protection Statistics Monthly - Taiwan Area, the Republic of China" (Taipei, Taiwan: Environmental Protection Administration, 2000).

2. Cochran, W. G., Sampling Techniques, third edition (New York, NY: John Wiley \& Sons, 1977).

3. Hsu, E., "An Analysis on Production Value and Employment Opportunities of Solid Waste Recycling" (final report EPA-044-880-129, Taipei, Taiwan: Environmental Protection Administration, 1999).

4. Hedayat, A. S., Sinha, B.K., Design and Inference in Finite Population Sampling (New York, NY: John Wiley \& Sons, 1991).

5. "National Income in Taiwan Area, R. O. C." (Taipei, Taiwan: Directorate-General of Budgets, Accounting, and Statistics, Executive Yuan, 2000).

6. "Yearbook of Manpower Survey Statistics, Taiwan Area, R. O. C.” (Taipei, Taiwan: Directorate-General of Budgets, Accounting, and Statistics, Executive Yuan, 2000). 